\title{
Measuring User Satisfaction of Educational Service Applications Using Text Mining and Multicriteria Decision-Making Approach
}

\author{
https://doi.org/10.3991/ijet.v16i17.22939 \\ Nasa Zata Dina ${ }^{1}\left({ }^{凶}\right)$, Riky Tri Yunardi ${ }^{1}$, Aji Akbar Firdaus ${ }^{1}$, Nyoman Juniarta ${ }^{2}$ \\ ${ }^{1}$ Universitas Airlangga, Surabaya, Indonesia \\ ${ }^{2}$ Université de Lorraine, Nancy, France \\ nasazatadina@vokasi.unair.ac.id
}

\begin{abstract}
Rapid growth of educational technology services today means that there are more applications in the market. Users may find it hard to choose the most suitable application, so they look for references. Experience shared in the form of text reviews and numerical rating can provide references. Text reviews are particularly specific and so they can provide insights to user satisfaction. In this study, we use text mining and multicriteria decision-making approach to measure the user satisfaction. The data is crawled and collected from seven educational applications: Coursera, edX, Khan Academy, LinkedIn Learning, Quipper, Socratic and Udemy. Nine attributes are used to measure the user reviews according to quality model of e-learning systems. The result is in favor of Khan Academy, while Quipper is ranked the lowest. The v-values used range between 0 and 1 and what is unique is that the rank of Khan Academy and Quipper are not affected by v-value while the ranks of the other applications are. It indicates that Khan Academy has high user satisfaction in terms of utility and low complaint from individuals. Quipper shows the opposite.
\end{abstract}

Keywords - educational application service, information and communication technology, multi criteria decision making, sentiment analysis, technology education

\section{$1 \quad$ Introduction}

The number of applications (apps) downloadable via mobile phone or website is increasing rapidly, and so is the number of users. In 2021, the number of available apps has reached 4.41 million [1]. Two of the major application platforms nowadays are Google Play and App Store, with categories of app offered including art/design, business, education, health, sports, weather, etc. [2]. During the COVID-19 outbreak, certain apps reached the greatest number of downloads, including the educational service apps. The downloads started in the first quarter of 2020, when the COVID-19 outbreak started in Indonesia and continued until the downloads reached 466 million on Google Play by the fourth quarter of 2020 . Google Play is indeed the platform with the highest 
reported educational app downloads in that year [3]. The surging downloads of educational services are most likely a result of work and study from home.

With the large number of apps available for download, users may find it difficult to choose which apps are reliable and suitable for their needs. There are a lot of available educational application services such as Coursera, edX, Khan Academy, LinkedIn Learning, Quipper, Socratic and Udemy, downloadable anywhere and anytime. These apps help students to create effective collaboration with teachers and other learners outside class. It also comes with a strong content management system and various course materials. The app developers collaborate with many educational institutions so that users will get relevant and up-to-date materials.

Prior to download, users often read the reviews from other users to decide whether an app is suitable for them. The reviews depict the user experience [4] that could be more comprehensive than numeric rating reviews. These text-based reviews provide valuable information both for users and developers. In a developer's perspective, it could help them to improve application standards, whereas in a user's perspective, it can help them to make decision.

Users voluntarily write genuine reviews based on their experience concerning various aspects of an app. However, due to the high volume, it is not possible for users to read all the reviews. Therefore, they often see the overall rating from numeric reviews although it will not provide specific information about an app's quality. From the problems mentioned, it is necessary to develop a method to help users in analyzing reviews. Past studies have focused on the analyses of consumer products via reviews to develop a decision-making system [5-10]. The current study aims to extend the body of literature by examining user reviews of educational apps.

Multi criteria decision-making (MCDM) is a collection of decision-making algorithms that help people to decide according to their preferences [11]. MCDM is used when there more than one alternative or more than one conflicting criterion. It is often used when dealing with a complex problem because it splits a complex problem into smaller components. It is widely used in various areas such as transportation [12], strategic management [13], supply chain management [14], production management [15], and tourism [16-17]. Several methods of MCDM are TOPSIS, ELECTRE, VIKOR, AHP, etc. Among those MCDM methods, VIKOR is one of the best ranking methods for this study because it examines the ranking process and considers identical rank for some alternatives [18].

The proposed method in this study consists of three stages: collecting and pre-processing text reviews, text-mining lexical attributes, and measuring user satisfaction towards educational application services from the lexical attributes. Seven educational service apps were included in the current study. First, we collected the most recent data crawled from the apps. The raw data collected were pre-processed to prepare them for text-mining and sentiment analysis. Then, we mined the lexical attributes and used a sentiment analysis to determine the polarity of each word. The negative and positive sentiments were scored to measure user satisfaction of each app. Finally, we weighed the scores by using VIKOR.

The remain section of this study are organized as follows. The proposed method and basic theory of method are introduced in Section 2. Then we integrated and explained 
in detail process steps therein such as data collection, data pre-processing, text mining, sentiment analysis and MCDM-VIKOR in Section 3. In Section 4, we presented the results in the form of table and chart, then explain the results. Finally, Section 5 concludes the paper.

\section{$2 \quad$ Method}

The proposed method can be seen in Figure 1. The data were collected from Google Play Store website. The reviews were crawled from seven educational service apps. Then, the data were pre-processed through a series of stages to make them ready for mining and analyzis. In the mining and analysis, the output is keyword vectors. These are prepared for the next stage where vectors are turned into a decision matrix. In the final stage, VIKOR approach as part of MCDM is run through the data.

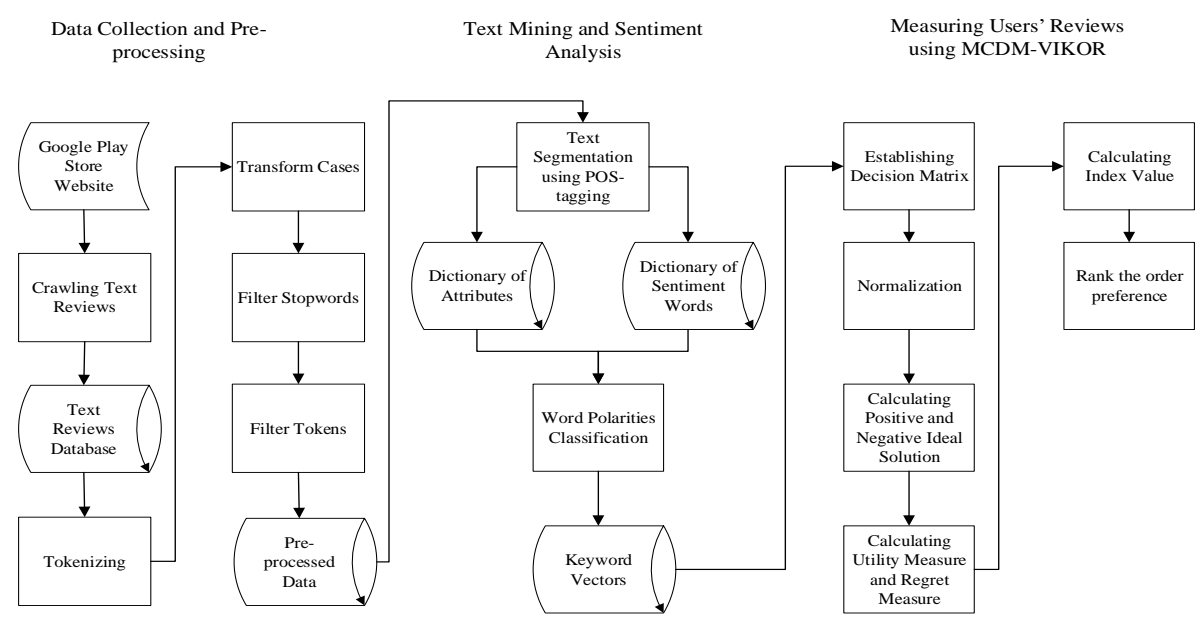

Fig. 1. Proposed Method

\subsection{Data collection}

The data were collected by considering similarities in features. Common aspects were extracted from the review data and used to measure and compare user satisfaction. The reviews about Coursera, edX, Khan Academy, LinkedIn Learning, Quipper, Socratic, and Udemy were extracted from Google Play website. 200 reviews from each application were collected so the total of the data used in this study are 1,400 reviews. The example of online review from each educational app can be seen in Table 1 . 


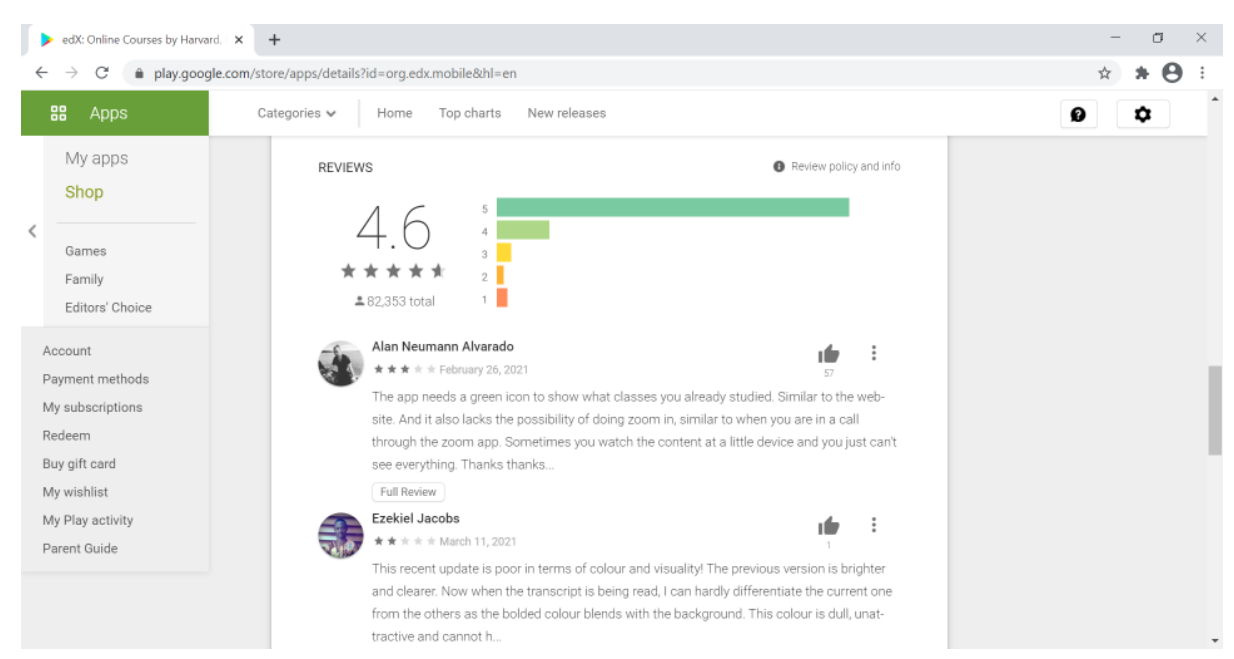

Fig. 2. Users' Reviews from Google Play Website

Table 1. Online review examples

\begin{tabular}{|c|c|c|}
\hline $\begin{array}{l}\text { Educational ser- } \\
\text { vices application }\end{array}$ & Review & Rate \\
\hline Coursera & $\begin{array}{l}\text { "The best thing about this app is, it just shattered the brick-and-mortar con- } \\
\text { cept of quality education. Thank you everyone associated with Coursera." }\end{array}$ & 5 \\
\hline edX & $\begin{array}{l}\text { "This is so good. I just watch one video, and I think this application is made } \\
\text { by a lot of people than want to share their knowledge. For free. May God } \\
\text { bless you all" }\end{array}$ & 5 \\
\hline Khan Academy & $\begin{array}{l}\text { "Great app! Exactly what I was looking for, much needed refresher of } \\
\text { knowledge and great explanation and examples specially for math's, which } \\
\text { is not my strongest subject. Very grateful for the team sharing their } \\
\text { knowledge and making this app available" }\end{array}$ & 5 \\
\hline LinkedIn Learning & $\begin{array}{l}\text { "Just started using the app. Love the minimal UI design. Good courses sub- } \\
\text { ject to your requirements." }\end{array}$ & 4 \\
\hline Quipper & $\begin{array}{l}\text { "I can't find or join in the class. I put the code correctly and the given code } \\
\text { is doubled checked by our teacher but still cannot join there. Can you please } \\
\text { help" }\end{array}$ & 2 \\
\hline Socratic & $\begin{array}{l}\text { "Very helpful app especially for students like I am. But I wish you guys } \\
\text { could add a search history feature where I can see my last searched ques- } \\
\text { tions. Quite useful" }\end{array}$ & 3 \\
\hline Udemy & $\begin{array}{l}\text { "Very handy overall, but when viewing PC based courses, would be handy } \\
\text { to be able to zoom in to the video as its sometimes difficult to see all the } \\
\text { writing on screen" }\end{array}$ & 4 \\
\hline
\end{tabular}

\subsection{Data pre-processing}

The data pre-processing transforms unformatted data into understandable formatted data to be processed in the next stages. This starts from data cleaning to remove irrelevant or noisy data. Noisy data are meaningless and cannot be interpreted because there 
are entry errors or faulty collection. The second stage is data transformation which includes tokenizing, case folding, stop words filtering and stemming. The result from data pre-processing is a collection of stem words that are free from stop words and irrelevant characters or strings.



Fig. 3. Data Pre-processing using RapidMiner

\section{$2.3 \quad$ Text mining}

The text-mining process in the current study consists text segmentation, summary extraction, keyword identification, topic detection, term clustering and document categorization. The aim is to compile dictionaries that consist of two types of words: a dictionary of attributes and a dictionary of sentiment words, which is different from the method proposed by [19]. They considered attribute and sentiment words as pairs. They paired attribute and sentiment to determine the polarities. If a sentiment word is labelled positive then its pair word is labelled as positive too, and vice versa. In the current study, this is not the case because each word has been determined its label. It is not based on its pairs.

Subsequently, the collection of stem words from the data pre-processing were classified into their part-of-speech (POS) tagging. Ireland and Liu [20] divided several POS-tags. POS-taggers used in this study is Stanford POS-tagger [21]. This POS tagger identifies adjective, adverb, noun, numeral, and verb. The dictionary of attributes is composed of noun phrases only while the rest went to dictionary of sentiment words.

Nine categories were selected to measure user satisfaction, as shown in Table 2. The categories are determined based on functionality, reliability, and usability [22]. After both dictionaries were developed then the words from sentiment words dictionary were classified into five groups of polarities: strong positive; positive; neutral; negative; strong negative. The spectrum of polarity usually consists of three types: positive, neutral, and negative. Dina [23] and Prastyo et al. [24] divided the polarity into three types. 
They applied sentiment analysis to determine the experience of hotel customers based on the most frequently mentioned words in its reviews. In this study we used five types of polarity so the result could be more specific and accurate. The polarity values are between 2 and -2 where strong positive $=2$; positive $=1$; neutral $=0$; negative $=-1$; strong negative $=-2$. Finally, if there were no sentiment words appear then the polarity value was set as 0 . The polarity value was used to construct keyword vectors of the user reviews. These were obtained by multiplying the occurrence attributes and the polarity value of sentiment words from the review data.

Table 2. Category and description

\begin{tabular}{|l|l|}
\hline \multicolumn{1}{|c|}{ Category } & \multicolumn{1}{c|}{ Description } \\
\hline Download (C1) & Ease of download \\
\hline Image (C2) & Quality of image displayed \\
\hline Video (C3) & Quality of video displayed \\
\hline Cost (C4) & Payment requirement before it can be used \\
\hline Assignment (C5) & A task or piece of work assigned to users as part of a course \\
\hline Content (C6) & Any informational material needed for learning \\
\hline Course (C7) & A series of lessons or lectures on a particular subject \\
\hline Exam (C8) & $\begin{array}{l}\text { A formal test that users take to check their comprehension of a particular subject, or to } \\
\text { obtain a qualification }\end{array}$ \\
\hline Teacher (C9) & A person who teaches or instructs \\
\hline
\end{tabular}

\subsection{Measuring user satisfaction using vlseKriterijumska optimizacija I kompromisno resenje (VIKOR)}

VIKOR stands for vlseKriterijumska optimizacija I kompromisno resenje. It is Serbian and was first established by Opricovic [25] as one of multicriteria decision making (MCDM) approaches. This method helps to solve a problem by considering the multicriteria [26]. It uses multicriteria ranking index to compare the closeness of each criterion so that the ideal alternative is obtained. A ranking index is obtained by calculating the maximum group utility $\left(S_{j}\right)$ and minimum individual regret $\left(R_{j}\right)$ [27]. There are several steps to be completed using VIKOR, as follows:

Establishing the decision matrix. The decision matrix is formed from the keyword vectors or it could simply be defined as the multiplication of attributes occurrence and polarity value for each attribute. Then, the number of attribute instances are counted for each category. The structure of decision matrix can be illustrated as follows:

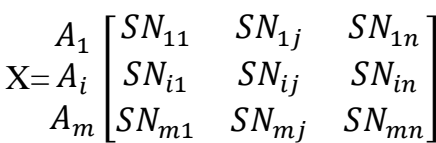

where:

$A_{i} \quad: i$-th alternative,

$S N_{i j} \quad:$ the value of $j$-th aspect for $i$-th alternative. 
Step 2: Calculating the normalized values and putting them into a decision matrix

The attributes occurrence $(x)$ from each category from Step 1 is normalized to a value between 0 and 1 . The formulation for normalization is shown in (1). The weighting scheme was applied to the data to measure the weight of each category $\left(w_{k}\right)$ and it is calculated using (2) where $n_{k}(d)=$ number of times $k$-th category occurs in document $d$

$$
\begin{gathered}
x^{*}=\frac{x-\min (x)}{\max (x)-\min (x)} \\
w_{k}=\frac{n_{k}(d)}{\sum_{k=1}^{m} n_{k}(d)}
\end{gathered}
$$

Step 3: Calculating the best $f_{j}^{*}$ and worst $f_{j}^{-}$of all criteria

The positive $\left(f_{j}^{*}\right)$ and negative $\left(f_{j}^{-}\right)$ideal solution is obtained using (3).

$$
f_{j}^{*}=\max _{i} f_{i, j} \text { and } f_{j}^{-}=\min _{i} f_{i, j}
$$

Step 4: Calculating new decision matrix with the weight $\left(w_{j}\right)$

The formula to assign the weight $\left(w_{j}\right)$ for a new decision matrix is written in (4).

$$
\frac{w_{j}\left(f_{j}{ }^{*}-f_{i j}\right)}{f_{j}{ }^{*}-f_{i j}{ }^{-}}
$$

Step 5: Calculating the values of the group utility $\left(S_{i}\right)$ and individual regret $\left(R_{i}\right)$

The calculation of utility measure $\left(S_{i}\right)$ and regret measure $\left(R_{i}\right)$ are done using $(5)$ and (6) where $w_{j}$ is the weight of the category.

$$
\begin{aligned}
& S_{i}=\sum_{i=1}^{n} \frac{\mathrm{w}_{\mathrm{j}}\left(f_{j}{ }^{*}-f_{i j}\right)}{f_{j}{ }^{*}-f_{i j}{ }^{-}} \\
& R_{i}=\max \left[\frac{\mathrm{w}_{\mathrm{j}}\left(f_{j}{ }^{*}-f_{i j}\right)}{f_{j}{ }^{*}-f_{i j}{ }^{-}}\right]
\end{aligned}
$$

Step 6: Calculating the index value $\left(Q_{i}\right)$ by using (7),

where $S^{*}=$ maximum value of $S_{i} ; S^{-}=$minimum value of $S_{i} ; R^{*}=$ maximum value of $R_{i} ; R^{-}=$minimum value of $R_{i} ; v=$ index weight value.

$$
Q_{i}=v\left[\frac{S_{i}-S^{*}}{S^{-}-S^{*}}\right]+(1-v)\left[\frac{R_{i}-R^{*}}{R^{-}-R^{*}}\right]
$$

Step 7: Ranking the order preference of index value (Qi)

The smallest the index value, the better the solution is. 


\section{Results and discussion}

Table 3 displays the calculated score for all the categories $\left(C_{n}\right)$ as described in Table 2. There are positive and negative values for the calculated scores. If the score is negative, then the number of negative polarities is bigger than the positive polarity in those categories. The last row shows the number of term instances in each category. Table 4 is generated from Table 3; the normalized score is obtained by applying formula in (1) while the weight from the last row is calculated by using (2).

Table 3. Calculated Scores

\begin{tabular}{|l|c|c|c|c|c|c|c|c|c|}
\hline & $\mathbf{C}_{\boldsymbol{1}}$ & $\mathbf{C}_{\mathbf{2}}$ & $\mathbf{C}_{\mathbf{3}}$ & $\mathbf{C}_{\boldsymbol{4}}$ & $\mathbf{C}_{\boldsymbol{5}}$ & $\mathbf{C}_{\mathbf{6}}$ & $\mathbf{C}_{\mathbf{7}}$ & $\mathbf{C}_{\boldsymbol{8}}$ & $\mathbf{C}_{\boldsymbol{9}}$ \\
\hline Coursera & -182 & 56 & -222 & -37 & -48 & -24 & 408 & -88 & 154 \\
\hline Edx & 0 & 0 & 80 & 0 & 0 & 8 & 332 & 0 & 0 \\
\hline Khan Academy & 203 & 0 & 638 & 218 & 124 & 160 & 1253 & 267 & 310 \\
\hline Linkedin Learning & 30 & 0 & -53 & 0 & 499 & 802 & 0 & 36 & 0 \\
\hline Quipper & 69 & -15 & 36 & -3 & 52 & 35 & -269 & 65 & -103 \\
\hline Socratic & 0 & 679 & 0 & 0 & 263 & 104 & 265 & 224 & 0 \\
\hline Udemy & 0 & 0 & -225 & -147 & 0 & 120 & 803 & 0 & 16 \\
\hline Term presence & 53 & 75 & 216 & 38 & 47 & 175 & 487 & 64 & 51 \\
\hline
\end{tabular}

Table 4. Normalized Scores

\begin{tabular}{|l|c|c|c|c|c|c|c|c|c|}
\hline & $\mathbf{C}_{\boldsymbol{1}}$ & $\mathbf{C}_{\boldsymbol{2}}$ & $\mathbf{C}_{\boldsymbol{3}}$ & $\mathbf{C}_{\boldsymbol{4}}$ & $\mathbf{C}_{\boldsymbol{5}}$ & $\mathbf{C}_{\boldsymbol{6}}$ & $\mathbf{C}_{\boldsymbol{7}}$ & $\mathbf{C}_{\boldsymbol{8}}$ & $\mathbf{C}_{\boldsymbol{9}}$ \\
\hline Coursera & 0.057 & 0.214 & 0.031 & 0.152 & 0.145 & 0.161 & 0.445 & 0.119 & 0.278 \\
\hline Edx & 0.177 & 0.177 & 0.229 & 0.177 & 0.177 & 0.182 & 0.395 & 0.177 & 0.177 \\
\hline Khan Academy & 0.310 & 0.177 & 0.596 & 0.320 & 0.258 & 0.282 & 1.000 & 0.352 & 0.380 \\
\hline Linkedin Learning & 0.196 & 0.177 & 0.142 & 0.177 & 0.505 & 0.704 & 0.177 & 0.200 & 0.177 \\
\hline Quipper & 0.222 & 0.167 & 0.200 & 0.175 & 0.211 & 0.200 & 0.000 & 0.219 & 0.109 \\
\hline Socratic & 0.177 & 0.623 & 0.177 & 0.177 & 0.350 & 0.245 & 0.351 & 0.324 & 0.177 \\
\hline Udemy & 0.177 & 0.177 & 0.029 & 0.080 & 0.177 & 0.256 & 0.704 & 0.177 & 0.187 \\
\hline Weight & 0.044 & 0.062 & 0.179 & 0.032 & 0.039 & 0.145 & 0.404 & 0.053 & 0.042 \\
\hline
\end{tabular}

Table 5. Positive Ideal Solution

\begin{tabular}{|l|c|c|c|c|c|c|c|c|c|}
\hline & $\mathbf{C}_{\boldsymbol{1}}$ & $\mathbf{C}_{\boldsymbol{2}}$ & $\mathbf{C}_{\boldsymbol{3}}$ & $\mathbf{C}_{\boldsymbol{4}}$ & $\mathbf{C}_{\boldsymbol{5}}$ & $\mathbf{C}_{\boldsymbol{6}}$ & $\mathbf{C}_{\boldsymbol{7}}$ & $\mathbf{C}_{\boldsymbol{8}}$ & $\mathbf{C}_{\boldsymbol{9}}$ \\
\hline $\mathrm{fj}^{*}$ & 0.310 & 0.623 & 0.596 & 0.320 & 0.505 & 0.704 & 1.000 & 0.352 & 0.380 \\
\hline $\mathrm{fj}-$ & 0.057 & 0.167 & 0.029 & 0.080 & 0.145 & 0.161 & 0.000 & 0.119 & 0.109 \\
\hline
\end{tabular}

Equation (3) was applied to determine the positive ideal solution $\left(f_{j}^{*}\right)$ and negative ideal solution $\left(f_{j}^{-}\right)$. The positive ideal solution was obtained by comparing the normalized value in Table 4 . The maximum value is regarded as a positive ideal solution $\left(f_{j}^{*}\right)$ and the minimum value is a negative ideal solution $\left(f_{j}^{-}\right)$. Both values are presented in Table 5. Next, Table 6 shows the results of the new decision matrix after multiplying the normalized values by the weight. 
The index value $\left(Q_{i}\right)$ determines the rank of each app based on the calculation formula in (7). The lowest index value shows the highest user satisfaction of various criteria. The $Q_{i}$ value involves the calculation of utility measure $\left(S_{i}\right)$ and regret measure $\left(R_{i}\right)$. Equation (5) and (6) are used to calculate both values. From Table 6, it can be seen that the specific criteria that need to be improved most is course $\left(C_{7}\right)$, video $\left(C_{3}\right)$ and content $\left(C_{6}\right)$ with reference to their $R_{i}$ values in Table 7.

Table 6. Normalized Decision Matrix with Weight

\begin{tabular}{|l|c|c|c|c|c|c|c|c|c|}
\hline & $\mathbf{C}_{\boldsymbol{1}}$ & $\mathbf{C}_{\mathbf{2}}$ & $\mathbf{C}_{\mathbf{3}}$ & $\mathbf{C}_{\boldsymbol{4}}$ & $\mathbf{C}_{\mathbf{5}}$ & $\mathbf{C}_{\boldsymbol{6}}$ & $\mathbf{C}_{\mathbf{7}}$ & $\mathbf{C}_{\mathbf{8}}$ & $\mathbf{C}_{\mathbf{9}}$ \\
\hline Coursera & 0.044 & 0.056 & 0.178 & 0.022 & 0.039 & 0.145 & 0.224 & 0.053 & 0.016 \\
\hline Edx & 0.023 & 0.061 & 0.116 & 0.019 & 0.036 & 0.139 & 0.244 & 0.040 & 0.032 \\
\hline Khan Academy & 0.000 & 0.061 & 0.000 & 0.000 & 0.027 & 0.113 & 0.000 & 0.000 & 0.000 \\
\hline Linkedin Learning & 0.020 & 0.061 & 0.143 & 0.019 & 0.000 & 0.000 & 0.332 & 0.035 & 0.032 \\
\hline Quipper & 0.015 & 0.062 & 0.125 & 0.019 & 0.032 & 0.135 & 0.404 & 0.030 & 0.042 \\
\hline Socratic & 0.023 & 0.000 & 0.132 & 0.019 & 0.017 & 0.123 & 0.262 & 0.006 & 0.032 \\
\hline Udemy & 0.023 & 0.061 & 0.179 & 0.032 & 0.036 & 0.120 & 0.119 & 0.040 & 0.030 \\
\hline
\end{tabular}

From the results given in Table 7, the sensitivity analysis was conducted to rank the highest and the lowest index values of seven educational apps. The $v$-value range from 0 to 1 . Figure 4 shows that the ranking of Khan Academy and Quipper are not affected by the $v$-value. Khan Academy was ranked as the number one while Quipper was ranked as the last. It means that Khan Academy has high user satisfaction in terms of maximum group utility and minimum individual regret while Quipper is the opposite. Meanwhile, the rank of Coursera and Udemy are lower when the $v$-value is increased. If Coursera and Udemy focuses on minimum individual regret, then both apps will have higher user satisfaction. On the other hand, LinkedIn Learning and Socratic's rank are higher when $v$-value is increased. It means that the user satisfaction of LinkedIn Learning and Socratic score will be higher if the maximum group utility is increased.

Table 7. Q values

\begin{tabular}{|c|c|c|c|c|c|c|c|c|c|c|c|c|c|}
\hline & \multirow{2}{*}{$S_{i}$} & \multirow{2}{*}{$\mathbf{R}_{\mathbf{i}}$} & \multicolumn{11}{|c|}{$\mathbf{Q}_{\mathrm{i}}$} \\
\hline & & & $v=0$ & $v=0.1$ & $v=0.2$ & $v=0.3$ & $v=0.4$ & $v=0.5$ & $v=0.6$ & $v=0.7$ & $v=0.8$ & $v=0.9$ & $v=1$ \\
\hline Coursera & 0.778 & 0.224 & 0.383 & 0.431 & 0.480 & 0.529 & 0.577 & 0.626 & 0.675 & 0.723 & 0.772 & 0.821 & 0.869 \\
\hline Edx & 0.710 & 0.244 & 0.452 & 0.484 & 0.515 & 0.547 & 0.578 & 0.610 & 0.641 & 0.673 & 0.704 & 0.736 & 0.767 \\
\hline $\begin{array}{l}\text { Khan } \\
\text { Academy }\end{array}$ & 0.200 & 0.113 & 0.000 & 0.000 & 0.000 & 0.000 & 0.000 & 0.000 & 0.000 & 0.000 & 0.000 & 0.000 & 0.000 \\
\hline $\begin{array}{l}\text { Linkedin } \\
\text { Learning }\end{array}$ & 0.642 & 0.332 & 0.755 & 0.746 & 0.737 & 0.728 & 0.719 & 0.710 & 0.701 & 0.692 & 0.682 & 0.673 & 0.664 \\
\hline Quipper & 0.864 & 0.404 & 1.000 & 1.000 & 1.000 & 1.000 & 1.000 & 1.000 & 1.000 & 1.000 & 1.000 & 1.000 & 1.000 \\
\hline Socratic & 0.614 & 0.262 & 0.513 & 0.524 & 0.535 & 0.546 & 0.557 & 0.568 & 0.579 & 0.590 & 0.601 & 0.612 & 0.623 \\
\hline Udemy & 0.639 & 0.179 & 0.228 & 0.271 & 0.315 & 0.358 & 0.401 & 0.445 & 0.488 & 0.531 & 0.575 & 0.618 & 0.661 \\
\hline
\end{tabular}




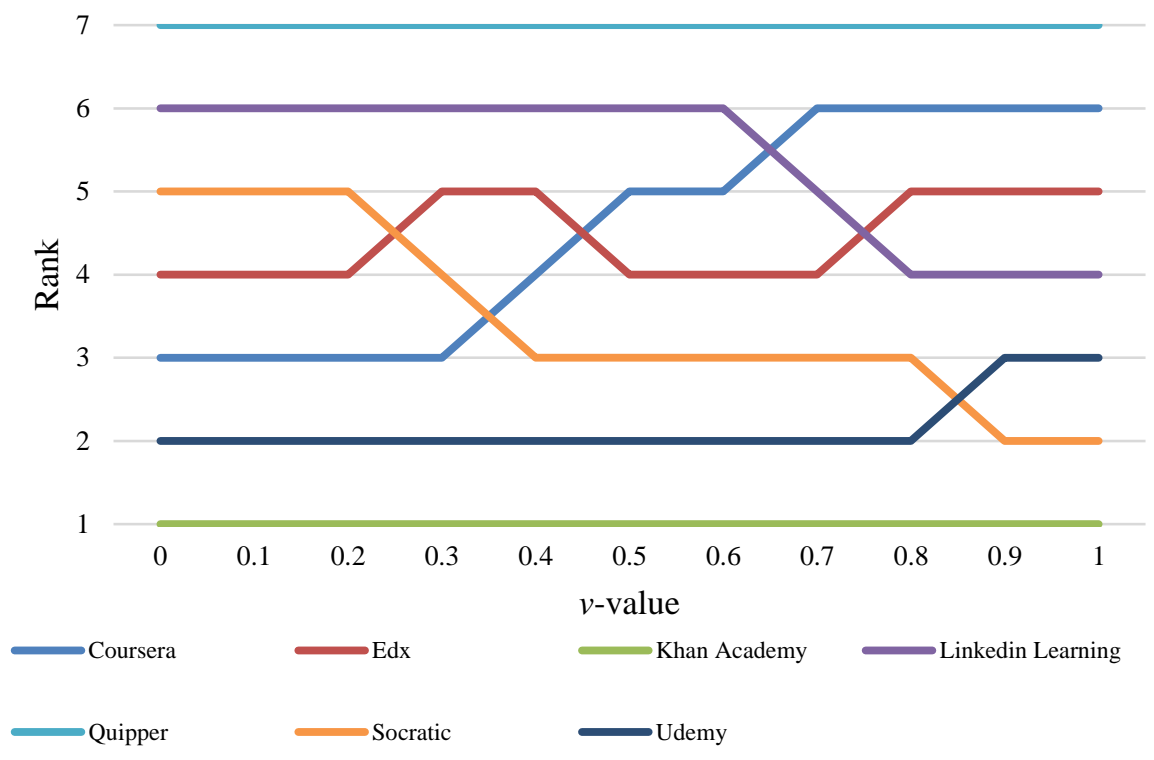

Fig. 4. Sensitivity Analysis

However, this study has several limitations such as the number of apps covered as case studies are only seven. Increasing the number of apps will improve the robustness of this study. The total number of reviews which are crawled from the website is only 1,400 . Considering the high volume of reviews online, the number of text reviews could be increased in order to capture the trends more accurately. In addition, future research will also benefit from combining both star rating reviews and text reviews to generate a more holistic measurement system. The categories selected in the current study are based on ISO 9126 as quality model for the e-learning systems. It could be compared with other quality models as well. Last, the MCDM approach used in this study is only VIKOR. Future study needs to be conducted to do a comparative analysis involving other MCDM methods in order to corroborate the findings.

\section{Conclusion}

This study proposes a framework for measuring user satisfaction of educational apps based on the user reviews. The data used in this study is actual user reviews. Text mining is used to extract lexical attributes from the reviews and a sentiment analysis is conducted to determine the word polarity. After doing text mining and sentiment analysis, then the word vector was measured using an MCDM algorithm, namely VIKOR. The weight of each criterion in VIKOR is obtained by calculating the term occurrence. It is used to help reducing subjectivity in the evaluation. From the seven educational apps, it can be concluded that Khan Academy shows the highest satisfaction and Quip- 
per shows the lowest. The result shows that user satisfaction is also influenced by maximum group utility and individual regret. The future study should be conducted using another MCDM method to validate the result. The number of the data crawled should be added to improve directory of attribute and sentiment word. The categories also should be wider than nine categories in this study.

\section{$5 \quad$ References}

[1] “App Download and Usage Statistics (2020)," Oct. 30, 2020. Accessed on: Mar. 1, 2021. [Online]. Available: https://www.businessofapps.com/data/app-statistics/

[2] "Choose a category and tags for your app or game". Accessed on: Mar. 1, 2021. [Online]. Available: https://support.google.com/googleplay/android-developer/answer/9859673?hl $=$ en\#zippy $=\% 2 \mathrm{Capps}$

[3] "Worldwide mobile education app downloads from 1st quarter 2017 to 1st quar-ter 2020, by platform," Feb. 4, 2021. Accessed on: Mar. 1, 2021. [Online]. Available: https://www.statista.com/statistics/1128262/mobile-education-app-downloads-worldwideplatforms-millions/. https://doi.org/10.1787/888934228210

[4] Zhang, C., Tian, Y., Fan, L., and Li, Y. (2020). Customized ranking for products through online reviews: a method incorporating prospect theory with an improved VIKOR. Applied Intelligence, 50(8): 1725-1744. https://doi.org/10.1007/s10489-019-01577-3

[5] Chen, K., Gang, K., Shang, J., and Yang, C. (2015). Visualizing market structure through online product reviews: Integrate topic modeling, topsis, and multi-dimensional scaling approaches. Electron Commerce Research and Applications, 14(1): 58-74. https://doi.org/ 10.1016/j.elerap.2014.11.004

[6] Liu, Y., Bi, J. W., and Fan, Z. P. (2017). Ranking products through online reviews: a method based on sentiment analysis technique and intuitionistic fuzzy set theory. Information Fusion, 36:149-161. https://doi.org/10.1016/j.inffus.2016.11.012

[7] Najmi, E., Hashmi, K., Malik, Z., Rezgui, A., and Khan, H. U. (2015). Capra: a comprehensive approach to product ranking using customer reviews. Computing, 97(8): 843-867. https://doi.org/10.1007/s00607-015-0439-8

[8] Yi, P., Gang, K., and Li, J. (2014). A fuzzy promethee approach for mining cus-tomer reviews in chinese. Arabian Journal for Science and Engineering, 39(6): 5245-5252. https://doi.org/10.1007/s13369-014-1033-7

[9] Zhang, K., Narayanan, R., and Choudhary, A. (2010). Voice of the customers: mining online customer reviews for product feature based ranking. In: Proceedings of the 3rd conference on online social networks. WOSN, pp. 1-9

[10] Zhang, K., Yu, C., Liao, W. K., and Choudhary, A. (2011). Mining millions of reviews: a technique to rank products based on importance of reviews. In: Proceedings of the 13th international conference on electronic commerce. ACM, New York, USA, pp. 1-8. https://doi.org/10.1145/2378104.2378116

[11] Mardani, A., Jusoh, A., Nor, K. M., Khalifah, Z., Zakwan, N., and Valipour, A. (2015). Multiple criteria decision-making techniques and their applications-a review of the literature from 2000 to 2014. Economic Research Ekonomska Istraživanja, 28(1): 516-571. https://doi.org/10.1080/1331677x.2015.1075139

[12] Nassereddine, M., and Eskandari, H. (2017). An integrated MCDM approach to evaluate public transportation systems in Tehran. Transportation Research Part A: Policy and Practice, 106(C): 427-439. https://doi.org/10.1016/j.tra.2017.10.013 
[13] Nasab, H. H., and Milani, A. S. (2012). An improvement of quantitative strategic plan-ning matrix using multiple criteria decision making and fuzzy numbers. Applied Soft Computing, 12(8): 2246-2253. https://doi.org/10.1016/j.asoc.2012.03.010

[14] Çalı, S., and Balaman, S. Y. (2019). A Novel Outranking Based Multi Criteria Group Decision Making Methodology Integrating ELECTRE and VIKOR under Intuitionistic Fuzzy Environment. Expert Systems with Applications, 119: 36-50. https://doi.org/ 10.1016/j.eswa.2018.10.039

[15] Zamani, M., Rabbani, A., Chamzini, A. Y., and Turskis, Z. (2014). An integrated model for extending brand based on fuzzy ARAS and ANP methods. Journal of Business Economic and Management, 15(3): 403-423. https://doi.org/10.3846/16111699.2014.923929

[16] Akincilar, A., and Degdeviren, M. (2016). A hybrid multi-criteria decision making model to evaluate hotel websites. International Journal of Hospitality Management, 36: 263-271. https://doi.org/10.1016/j.ijhm.2013.10.002

[17] Liang, X., Liu, P., Wang, Z. (2019). Hotel Selection Utilizing Online Reviews: A Novel Decision Support Model Based on Sentiment Analysis And DL-VIKOR Method. Technological and Economic Development of Economy, 25(6): 1139-1161. https://doi.org/ 10.3846/tede.2019.10766

[18] Zamani-Sabzi, H., King, J. P., Gard, C. C., and Abudu, S. (2016). Statistical and analytical comparison of multi-criteria decision-making techniques under fuzzy environment. Operations Research Perspectives, 3: 92-117. https://doi.org/10.1016/j.orp.2016.11.001

[19] Dina, N.Z., Yunardi, R.T., and Firdaus, A.A. (2021). Utilizing Text Mining and FeatureSentiment-Pairs to Support Data-Driven Design Automation Massive Open Online Course. International Journal of Emerging Technologies in Learning, 16(1): 134-151. https://doi.org/ $\underline{10.3991 / \text { ijet.v16i01.17095 }}$

[20] Ireland, R., and Liu, A. (2018). Application of data analytics for product design: Sentiment analysis of online product reviews. CIRP Journal of Manufacturing Science and Technology, 23: 128-144. https://doi.org/10.1016/j.cirpj.2018.06.003

[21] Toutanova, K., Klein, D., Manning, C. and Singer, Y. (2003). Feature-Rich Part-of-Speech Tagging with a Cyclic Dependency Network. In: Proceedings of HLT-NAACL, Canada, 2003. Edmonton: ACM, pp. 252-259. https://doi.org/10.3115/1073445.1073478

[22] Djouab, R., and Bari, M. (2016). An ISO 9126 Based Quality Model for the e-Learning Systems. International Journal of Information and Education Technology, 6(5): 370-375. https://doi.org/10.7763/ijiet.2016.v6.716

[23] Dina, N.Z. (2020). Tourist sentiment analysis on TripAdvisor using text mining: A case study using hotels in Ubud, Bali. African Journal of Hospitality, Tourism and Leisure, 9(2): $1-10$

[24] Prastyo, P. H., Sumi, A. S., Dian, A. W., and Permanasari, A. E. (2020). Tweets Responding to the Indonesian Government's Handling of COVID-19: Sentiment Analysis Using SVM with Normalized Poly Kernel. Journal of Information Systems Engineering and Business Intelligence, 6 (2): 112-122. https://doi.org/10.20473/jisebi.6.2.112-122

[25] Dincer, H., and Hacioglu, U. (2013). Performance evaluation with fuzzy VIKOR and AHP method based on customer satisfaction in Turkish banking sector. Kybernetes, 42(7): 10721085. https://doi.org/10.1108/k-02-2013-0021

[26] Haleh, H., and Hamidi, A. (2011). A fuzzy MCDM model for allocating orders to suppli-ers in a supply chain under uncertainty over a multi-period time horizon. Expert Systems with Applications, 38(8): 9076-9083. https://doi.org/10.1016/j.eswa.2010.11.064

[27] Liou, J. J. H., Tsai, C., Lin, R., and Tzeng, G. (2011). A modified VIKOR multiple-criteria decision method for improving domestic airlines service quality. Expert Systems with Applications, 17(2): 57-61. https://doi.org/10.1016/j.jairtraman.2010.03.004 


\section{Authors}

Nasa Zata Dina is a lecturer in the Department of Engineering, Faculty of Vocational Studies at Universitas Airlangga, Surabaya, Indonesia. Her research interests include data mining, text mining, and engineering education. She is also an editorial board member of Journal of Information Systems Engineering and Business Intelligence.

Riky Tri Yunardi is a lecturer in the Department of Engineering, Faculty of Vocational Studies at Universitas Airlangga, Surabaya, Indonesia. His research interests include medical electronics, robotics, image processing, and artificial intelligence, and engineering education.

Aji Akbar Firdaus is a lecturer in the Department of Engineering, Faculty of Vocational Studies at Universitas Airlangga, Surabaya, Indonesia. His research interests include power systems simulation, power systems analysis, power systems stability, renewable energy, and artificial intelligence.

Nyoman Juniarta is a post-doctoral fellow and researcher in Université de Lorraine, Nancy, France. His research interests include data mining, text mining, and information retrieval.

Article submitted 2021-03-28. Resubmitted 2021-06-07. Final acceptance 2021-06-07. Final version published as submitted by the authors. 